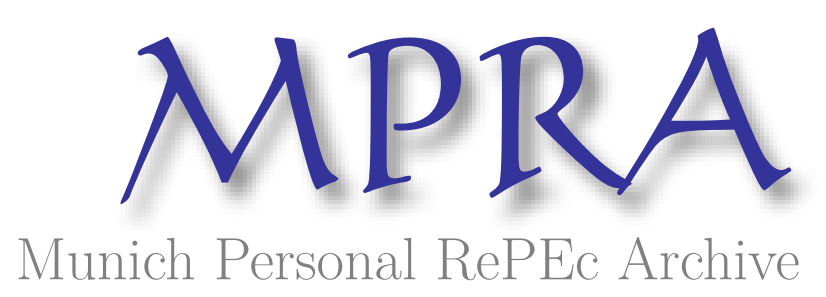

\title{
Regional dimensions of economic development in Iran: A new economic geography approach
}

Farmanesh, Amir

University of Maryland, College Park, World Bank, MNSED

2 January 2009

Online at https://mpra.ub.uni-muenchen.de/16942/

MPRA Paper No. 16942, posted 26 Aug 2009 00:19 UTC 
Revision August 2009

\title{
Regional dimensions of economic development in Iran, a New Economic Geography approach ${ }^{1}$
}

\author{
Amir Farmanesh ${ }^{2}$ \\ University of Maryland, College Park
}

\begin{abstract}
This paper presents a spatial analysis of the regional dimensions of poverty and economic development across provinces of Iran. It offers one of the few estimations made in developing countries using this strand of New Economic Geography (NEG) models and provides a comparison of the results for Iran with those in previously studied developed countries.

The goal of this study is to offer an analysis of the effects of agglomeration and dispersion economies on the patterns of regional economic development in Iran based on the empirical estimation of two of the NEG models. First, it presents an estimation of a Market Potential Function (MPF), in which wages are associated with proximity to consumer markets. Second, it estimates an augmented MPF derived from the Krugman model of economic geography that estimates the importance of transportation costs and economies of scale.

The estimation results suggest that Iran shows a generally good fit to both models, satisfying their specifications. Compared to similar studies of developed countries, Iran shows smaller returns to scale. This might be a result of the nature of the technologies used in the nonfarm private sector in Iran, which is less industrial and more traditional. Dispersion and decentralization of industries to achieve lower income inequality between provinces would create a level of loss, but less losses than they would be in Western countries.

The paper also found a significantly and consistently greater effect of market potential on wages in comparison to the effect estimated in similar analyses of other countries. This might be a result of the country's more distance-sensitive trade structure, which relies on an underdeveloped transportation system between provinces in Iran. It is also a highly mountainous and geographically diverse country.

The overall result of this study corroborates the notion of centralization in the Iranian economy. The large wage variations explained by economic geography could cause significant internal migration, beyond that seen in western countries. Indeed, significant internal migration has been observed in Iran in past years.
\end{abstract}

Keywords: New Economic Geography; Spatial agglomeration; Market potential; Market structure; Increasing returns to scale; Transport costs; Iranian economy; Economic development in Iran; Income distribution in the provinces of Iran; Empirical evaluation

JEL classification: F12, R12, O10, O15

\footnotetext{
${ }^{1}$ This study was sponsored by the World Bank, Middle East and North Africa Region, Social and Economic Development Group. Further acknowledgments are provided at the end of paper.

Paper will be presented in "Iranian Economy at a Crossroads: Domestic and Global Challenges" conference, University of Southern California, September 18-19, 2009.

2 年armanes@umd.edu - www.farmanesh.ir
} 


\section{Contents}

I. Introduction 13

II. Overview of regional diversity in Iran

III. Theory and Specifications ___ 21

IV. Analysis and Results__ 24

V. Conclusions__ 28

VI. References__ 31

VII. Appendixes__ 33 


\section{Introduction}

The spatial relation between economic agents is an important determinant of how they interact, what they do, and how well off they are. Based on NEG theories, economic activities and interactions fall off rapidly with distance, and production structures are shaped both by factor endowments and by distance to markets and sources of supply. In recent years a number of theoretical tools have been developed to address the role of geography in shaping these relationships. There is also a newly developing body of empirical work, based mainly on crosscountry and sub-national studies. This is now being supplemented by empirical work which is being developed by recent developments in theory using international as well as sub-national data.

This paper studies the spatial distribution of economic activity in the Iranian provinces and the strength of product-market linkages between them. It presents a spatial analysis on regional dimensions of poverty and economic development across 28 provinces of Iran. As far as the author of this paper found, this paper is the first estimation made in any developing country using this strand of "New Economic Geography" (NEG) models.

The goal of this study is to offer an analysis of the effects of agglomeration and dispersion economies on the patterns of regional economic development in Iran. It analyzes the linkages among adjacent provinces as well as effects of agglomeration and dispersion economies on the patterns of Iran's regional economic development through empirical estimation of two NEG models.

NEG models are based on the idea that the level of market access to goods is an imperative condition for the scale of economic activity in any location. They emphasize the importance of the market access characteristics compared to the set characters of a location. This approach presents an alternative approach in characterizing the economy of scale and the geographic agglomeration of 
economic activities.

The effects of physical location and distance on the economic situation have long been studied. The Neo-Classical Theory (NCT) takes location as exogenous and explains agglomeration derived from endowment and/or technology. The introduction of increasing returns to scale at the firm level and consumers' preference in the variety of goods were the New Trade Theory (NTT) improvements which all were the basis for the development of NEG theory.

Overman et al. (Overman, Redding, \& Venables, 2003) mentions the differentiation between first- and second-nature geography and their important roles as determinants of trade, income and production structure. The first-nature is defined as the physical geography of coasts, mountains, and endowments of natural resources, while second-nature is defined as the distance between economic agents. With this definition, first-nature elements are the main subject of factor endowment based trade theory. While, NEG models primarily use the second-nature definition. NEG models are concerned with how the spatial relationship between economic agents determines their interaction, what they do, and how well off they are?

NEG theories combine the above mentioned aspects with the new feature of "agglomeration" effects which endogenously arise for some parameter values. NEG theories take location as endogenous and assume labor mobility. The models suggest higher wages at the centre of production and lower wages on the periphery. They predict that the access of a location to markets for its goods determines its level of economic activity. Therefore, less proximity to consumer markets would result in higher economic activity, which in turn increases the level of employment and wages.

NEG predicts that with higher economies of scale, agglomeration would increase as economies of scale encourage firms to concentrate their production in few locations to utilize scale 
gains. Also lower trade costs allow firms to supply even the markets that are far from one central location, this in turn would increase agglomeration as predicted by NEG. NEG also predicts stronger agglomeration if demand patterns are biased for industrial and manufactured goods as they support larger agglomerations of firms.

Harris (Harris, 1954) presents the idea which later NEG models used. It proposes that, weighted by transportation costs, the demand for produced goods in a specific location is the total of purchasing power in other locations. Krugman's (Krugman, 1991) paper re-initiated mainstream economics interest in the spatial distribution of economic activity. It uses the interaction of firmlevel economies of scale and transport costs as an explanation for agglomeration and city formation. Hummels (Hummels, 1999) studied the relationship between per capita income and market access and showed the high correlation between residuals from the augmented Solow growth model with measures of geographical location.

Fujita et al. (Fujita, Krugman, \& Venables, 1999) showed that spatial demand linkages are created by a combination of transportation cost and scale economies contributing to agglomeration. The possibility of serving large local markets draws firms to cities, however costs related to congestion limit the geographic concentration. Fujita et al. (Fujita, et al., 1999) by deriving the Harris (Harris, 1954) "Market Potential Function” (MPF) from formal spatial models revived its concept. Modern forms of MPF show that near consumer and industrial agglomerations nominal wages are higher.

The determinant characteristics of firm size have been studied separately through different approaches. For example, Axtell (Axtell, 2001) showed that Zipf distribution characterizes firm sizes and that some large firms pay higher wages for the same job. Connecting this to NEG insights about the interplay between distance, agglomeration and wages, we can study factors effecting wage 
inequality in different regions.

Distance and geographical location affect wages and income through influence on the flow of production factors, goods, and ideas. There are different mechanisms to determine the influence of distance. On the one hand is a province's distance from the markets buying their output, and on the other hand is the distance from provinces supplying their needs, providing the necessary capital and intermediate goods for production. The importance of distance translates into transport costs and other trade barriers. This means that provinces further from markets would effectively pay a tax or penalty on their sales and imports. As a result, firms in these provinces would pay lower wages than others with better access, even if other factors like technology are similar.

The potential impact of these effects has been empirically estimated at country level. Hummels (Hummels, 1999) used customs data to show that while the average expenditure on freight and insurance as a proportion of the value of manufacturing imports is $10.3 \%$ in the US, it is 17.7\% in Brazil. Limao and Venables (Limao \& Venables, 2001) showed that the shipping costs of a median land-locked country are more than 50\% higher than those of the median coastal country. As Redding and Venables (Redding \& Venables, 2004) mention, these papers narrowly define transportation costs as pure costs of freight and insurance, this may result in possible understatement of the real scale of trade barriers as the cost of distance could possibly be higher due to the costs of transit time or information gathering.

Head and Mayer (Head \& Mayer, 2004), Overman et al. (Overman, et al., 2003), Redding and Venables (Redding \& Venables, 2004), and Garcia Pires (Garcia Pires, 2006) offer comprehensive surveys of the increasing number of empirical studies published on NEG models in the last strand. An important problem of NEG empirical research is the unobserved variables that affect spatial agglomeration besides market access and distance. For example, workers could come to a province 
based on factors like family needs or weather choice (Roback, 1982). However, some researchers like Redding and Venables (Redding \& Venables, 2004) and Garcia Pires (Garcia Pires, 2006) have reported their results to be robust and that additional control variables made no significant change in their results. Regardless, this paper addresses issues of unobserved variables through the interpretations in the text.

Neary (Neary, 2001) and Brakman et al. (Brakman, Garretsen, \& Schramm, 2004) in a review of NEG empirical works conclude that empirical research is lagging behind NEG theory and that much more empirical validation of NEG theoretical insights is necessary. The reason given for the lag of empirical research is that the NEG models characteristics which are nonlinear and use multiple equilibria. As mentioned in this paper and other empirical NEG works this makes empirical validation relatively difficult and less accurate.

Hanson (Hanson, 2005) categorizes published NEG empirical research into three strands. The first strand is based on Krugman's (Krugman, 1980) home-market effect and the New Trade Theory (NTT) which studies the determinants of production concentration close to large national or regional markets. The second strand is consistent with Eaton and Kortum (Eaton \& Kortum, 1999, 2002) which focuses on the diffusion of technology across space and its effects on trade and industry location. The third strand is what Hanson (Hanson, 1998, 2005), Redding and Venables (Redding \& Venables, 2004), Head and Mayer (Head \& Mayer, 2004), Garcia Pires (Garcia Pires, 2006), and this paper are close to. Based on NEG models, they study whether wage/income is higher in countries/provinces with better access to larger markets for their goods.

This paper first presents Harris (Harris, 1954) estimation of an MPF model in which wages are associated with proximity to consumer markets. The MPF model captures the intuitive idea that distance acts as a barrier to trade. After taking into account the barriers of distance, the "market 
potential" is the total amount of trade between all regions that might take place. By assuming that wages would be proportional to the market potential, we can study whether trade in Iran is subject to the distance barrier or not.

Second, the paper estimates an augmented market-potential function derived from the Krugman (Krugman, 1991) model of economic geography. The parameters in this model estimate the importance of transportation costs and scale economies. The Krugman model offers insight into economies of scale and describes the benefits that firms and industries gain by locating near each other. Based on the idea of economies of scale, as more similar firms cluster together, there would be more competing suppliers, greater specialization and division of labor. These factors decrease the cost of production and increase the markets for firms.

Krugman (Krugman, 1991), by studying the relation between agglomeration, increasing returns and market access, endogenously determines wages in a province as a function of wages and income in other provinces. He tests the spatial distribution of economic activity through the estimation of several structural parameters including elasticity of substitution, trade costs and share of income spent on industrial and manufactured goods.

The structural estimation used in this paper is similar to what Hanson (Hanson, 1998, 2005) offered for the first time for the United States. Later empirical studies were done similar to Hanson's (Hanson, 1998, 2005) in other developed countries. Roos (Roos, 2001) offers an estimation for Western Germany, De Bruyne (De Bruyne, 2002) for Belgium, Brakman et al. (Brakman, et al., 2004) for Germany, Mion (Mion, 2004) for Italy, and Paluzie et al. (Paluzie Hernandez, Pons Novell, \& Tirado Fabregat, 2005) and Garcia Pires (Garcia Pires, 2006) for Spain. The results of these studies have been compared with the results of this study later in the paper.

While this paper and Garcia Pires (2006) use Krugman (1993), the multi-region version of 
the Krugman (1991), the other papers noted above use Helpman's (1998) variant of the Krugman (1991) econometric formalization. Krugman (1991) assumes that a perfect competitive sector produces a homogeneous good like agriculture which is traded freely. While Helpman (1998) takes the homogeneous good as a non-tradable good like housing. Considering the higher housing price in more populated provinces, an extra centrifugal force is introduced. As a result, the two models have differences in the impact of a trade cost reduction as Helpman (1998) would predict promotion of dispersion but Krugman (1991) would predict promoted agglomeration.

Puga (1999) has shown that the Krugman (1991) and Helpman (1998) models are not necessarily different but that they are two sides of the relationship between regional inequality and transportation costs. Through this bell-shaped curve Helpman (1998) predicts more dispersion in the case of a reduction from low trade costs, while Krugman (1991) predicts an increase in agglomeration in the case of a reduction from high trade costs. As mentioned most empirical works have chosen Helpman’s (1998) model over Krugman's (1991) as they see Helpman (1998) predicting less extreme spatial patterns than Krugman (1991). However, Garcia Pires (2006) has shown that while the two-region case of Krugman's (1991) model offers an extreme configuration of space; Krugman's (1993) model is generalized to multiple regions which makes it suitable for empirical estimation.

Previous empirical studies have focused mostly on NEG estimations in the developed countries. In general, it is appealing to empirically study these models in diverse countries and economies, especially to offer estimations for developing countries versus current estimations for developed countries and study the potentially consistent differences. In particular, considering diversity, mountainous geography, and regional cultures of provinces in Iran, Iran can be an interesting case study for testing NEG models. 
A major advantage of this study for Iran is the nature of trade in Iran. NEG models assume a closed economic framework to be able to simplify the factors. This assumption is much more accurate for the nature of trade in Iran in comparison to trade in Europe and America, where the available empirical literature of this model exists. While some other developing countries also fit better in this assumption of a closed economy than developed countries, but Iran, in result of political factors and trade sanctions, would be an even better case to study.

The estimation results suggest that Iran showed generally good fit to both models and satisfied both MPF and Krugman model specifications. Compared to other similar studies in developed countries, Iran shows smaller returns to scale and significantly higher effects of market potential on wages.

\section{Overview of regional diversity in Iran}

Iran with the eighteenth largest land mass and seventeenth largest population in the world is a country of great history and diversity. For a more effective management of this wide country, Iran is currently subdivided into provincial divisions, which are called استان (ostān) in Persian, and in plural form استانها (ostānhā). The thirty current provinces or Ostans are each governed from their capital, which is usually the largest local city. Each capital is called the مركز (markaz) of that province. Every province is headed by a Governor-General or استاندار (ostāndār), who is appointed by the Minister of the Interior subject to approval of the cabinet.

The structure of provinces of Iran has changed a number of times in recent history. Until 1950, Iran was divided into twelve provinces: Ardalan, Azarbaijan, Baluchestan, Fars, Gilan, Araq-e Ajam, Khorasan, Khuzestan, Kerman, Larestan, Lorestan, and Mazandaran. In 1950, there was a reorganization to form ten provinces with subordinate governorates: Gilan, Mazandaran, East Azarbaijan, West Azarbaijan, Kermanshah, Khuzestan, Fars, Kerman, Khorasan, and Isfahan. 
Between 1960 and 1981, several governorates were raised to provincial status one by one, which has resulted in the creation of several new provinces. The most recent one was the division of Khorasan into three new provinces in $2004 .^{3}$

Each province or Ostan is further subdivided into counties or شهرستان (shahrestān), and each shahrestan is then subdivided into districts or بخش (bakhsh). Each county usually consists of few cities or دهر (shahr) and some rural agglomerations or دهنتان (dehestān) which are a collection of a number of villages. According to the Statistical Center of Iran, as of the end of Iranian Calendar year $1383^{4}$ (March 2005), Iran has 30 provinces, 324 counties, 865 districts, 982 townships, and 2378 rural agglomerations.

Due to the limited availability of data, this study covers the Iranian Calendar years of 13791382 (approximately 2000-2004) when Iran had 28 provinces. The only difference since then has been the split of province of Khorasan into three new provinces in 2004. Please refer to (Table 1) for more information on provinces of Iran during the Iranian Calendar years of 1379-1382.

\section{Theory and Specifications}

Our methodology generally follows Garcia Pires (2006), unless mentioned specifically otherwise. Paper uses (Greene, 2003; Wooldridge, 2003) as the general for econometric references. The first model is a market potential function (MPF), which comes from a line of theory based on Harris (1954). The second model is based on the Krugman (1993) multi-region version of Krugman's (1991) model. Since the economic theory underlying these models is beyond the scope of this paper, we simply discuss the salient features of the models and present them in an estimable

3 Please see http://www.statoids.com/uir.html for more information on the history of provinces in Iran.

4 Persian calendar is an astronomical solar calendar used in Iran and Afghanistan as the main official calendar. The current Iranian Calendar year is AP 1386 (AP = Anno Persico/Anno Persarum = Persian year). The Iranian year usually begins on March 21 of the Gregorian calendar. By adding 621 to an Iranian year, the corresponding year as reckoned by the Gregorian calendar can be found. 
form.

The MPF model captures the idea that distance acts as a barrier to trade. After taking into account the barriers of distance, the "market potential" is the total amount of trade between all regions that might take place. By assuming that wages would be proportional to the market potential, using exponential decay as the functional form of the distance barrier to trade, and taking logs, we find Equation 1. In Equation 1, $\theta$ is a scale parameter and $\alpha$ and $\beta$ are the model parameters. The income (GDP) of region $\mathrm{j}$ is $Y_{j}, w_{i}$ is the wage of region $i$, and $d_{i j}$ is the distance between regions $i$ and $j^{5}$ The only strict theoretical restrictions are that $\alpha$ and $\beta$ should be positive, indicating that wage and market potential are positively related, and that trade drops off with distance, respectively. Equation 1 is a standard empirical MPF in the literature. ${ }^{6}$

$$
\log \left(w_{i t}\right)=\theta+\alpha \log \left(\sum_{i=1}^{N} Y_{j t} \exp \left(-\beta d_{i j}\right)\right)+\varepsilon_{i t}
$$

In the Krugman model, forces for the agglomeration and dispersion of economic activity act in concert to produce the observed economic geography. The Krugman model considers a homogeneous and a differentiated good, which are often interpreted as agricultural and manufactured goods, respectively. ${ }^{7}$ In the model, "peasants" are fixed in place while "workers" can move from one region to another. Workers, who are paid the marginal product of their work, are drawn together to benefit from higher wages that result from economies of scale. They are pushed apart by the downward wage pressures of increased competition. We estimate a form of the Krugman model given in Equation 2, where $\theta$ is again a scale parameter, $\sigma$ represents inverse economies of scale, $\mu$ is the fraction of income spent on manufactured goods, and $\tau$ is a trade cost

5 Note that we measure GDP and wages in a province in terms of the numéraire of peasant wages in the region, so that we measure real GDP and wages consistent with the Krugman (1991) formulation.

6 See Garcia Pires (2006), for example.

7 See (Krugman, 1991). 
index. $^{8}$ In addition, we report $\sigma /(\sigma-1)$ and $\sigma(1-\mu)$, because they have the interpretations of nationally increasing returns to scale in manufacturing and strong agglomeration forces.

$$
\log \left(w_{i t}\right)=\theta+\sigma^{-l} \log \left(\sum_{i=1}^{N} Y_{j t} w_{j t}^{\frac{\sigma-1}{\mu}} \exp \left(-\tau(\sigma-1) d_{i j}\right)\right)+\varepsilon_{i t}
$$

One important econometric issue is that wages and GDP are jointly determined which could lead to endogenous variable biases. ${ }^{9}$ To attempt to control for this, we estimate several different specifications. In particular, we estimate time-differenced versions of Equations 1 and 2, which are given in Equations 3 and 4, respectively.

$$
\begin{aligned}
& \log \left(\frac{w_{i t}}{w_{i t-1}}\right)=\alpha\left[\log \left(\sum_{i=1}^{N} Y_{j t} \exp \left(-\beta d_{i j}\right)\right)-\log \left(\sum_{i=1}^{N} Y_{j t-1} \exp \left(-\beta d_{i j}\right)\right)\right]+\varepsilon_{i t} \\
& \log \left(\frac{w_{i t}}{w_{i t-1}}\right)=\sigma^{-1}\left[\log \left(\sum_{i=1}^{N} Y_{j t} w_{j t}^{\frac{\sigma-1}{\mu}} e^{-\tau(\sigma-1) d_{i j}}\right)-\log \left(\sum_{i=1}^{N} Y_{j t-1}^{\frac{\sigma-1}{\mu}} e^{-\tau(\sigma-1) d_{i j}}\right)\right]+\varepsilon_{i t}
\end{aligned}
$$

To avoid the potential issue of technological or other shocks that disproportionately hit the largest areas; we estimate the models with and without the provinces of Tehran and Khuzestan, which are the two regions with the highest Gross Regional Domestic Product (GRDP) with a substantial gap to the third region. (Table 1) and (Figure 4, Figure 5, and Figure 6) show the significant difference between these two provinces and other provinces in the country.

To estimate how goods move around the country, we use three different measures of distance: simple distance, 'hub and spoke' (HAS), and extreme hub and spoke. In simple distance, the distance between any two provinces is simply the distance between the capital cities of each. In

8 For a derivation of this model from Krugman's equilibrium conditions, see (Garcia Pires, 2006).

9 See (Hanson, 2005) for a complete discussion of the econometric issues involved. 
hub and spoke distance, there are five "hub" provinces ${ }^{10}$, between which all trades must pass (Table 2) and (Figure 1). That is, to trade between two outlying provinces, goods are transported from one Ostan to its hub, from that hub to the destination Ostan's hub, and on to the destination Ostan. Finally, the extreme HAS distance supposes that all trade between outlying provinces passes through Tehran with the assumption that most storage and managing facilities are agglomerated in Tehran.

By seeing to what extent each of the distance measurements result in better empirical fits, we can learn something about trade patterns within Iran. However, our ability to do this might be limited by the overall relevance of distance to trade. To cope with this issue, Hanson (2005) uses a categorical variable for distance that takes only a few values. Though we hope to gain policy insights by using more exact distance measures, the exact distance level may not directly matter. Apart from the mentioned econometric problems with endogenous variables and high nonlinear modeling, there is an additional problem with identification of the parameters. For example, in the MPF model, $\theta$ and $\alpha$ are not identified when $\beta$ equals zero as well as $\beta$ is not identified if $\alpha$ equals zero.

\section{Analysis and Results}

The distance data used in this study are provided by the 'Iran National Cartographic Center', all other data are provided by the 'Statistical Center of Iran'. All data used are available for public use from both centers without mentioned restrictions.

To fit the data, we use GRDP (Figure 2) and (Figure 4, Figure 5, and Figure 6) and non-farm wages (Figure 3) and (Figure 7, Figure 8, and Figure 9) in units of effective farmer production, as well as the several distance measures discussed above. Note that in addition to controlling for the difference in farm wages across Iran, using a relative unit of wages and income also might play as an automatic control for inflation, which is relatively large in Iran. For time-differenced estimation, we

10 These are East Azarbaijan, Esfahan, Fars, Khorasan, and Tehran. 
difference each year and the previous year. While differencing allows us to control for some persistence in wage differences, there are costs to differencing as well. Instead of using the full cross-sectional variation in wages and GDP, differencing limits itself to considering the effects on wages of a change in GDP. It fails to take full advantage of the information in the magnitudes of wage and GDP for each period, thus wasting some of our limited information. ${ }^{11}$ Since differencing the data loses a significant amount of information in the data, and since we have only data from 28 provinces per year, the benefit of controlling for persistence in wage shocks over time is at least partially offset by the loss in accuracy.

Since Equations 1 to 4 are nonlinear, we use nonlinear least squares (NLS) to compute parameter estimates. Since NLS estimation must be done by iteration, we chose the Gauss-Newton algorithm for optimization. Because Gauss-Newton sometimes fails to converge, we tested over 1000 different starting parameter estimates for every combination of year, distance measure, set of provinces, and equation. ${ }^{12}$ Considering the optimization effort made, the failure to converge might be interpreted as a sign of a poor fit between the model and data. However, it could also be a lack of identification as a result of inadequate information in the data to identify the model, particularly in the differenced data, where there is little variation.

In the following paragraphs, we discuss general conclusions that can be drawn from the diverse specifications that we used. For each model, we discuss whether parameter estimates were consistent with the theory, reproducible over time, or robust to different versions of each model. We also look qualitatively at convergence across model versions to see which fit the data better.

The single period MPF model (Table 3) was consistent with the data. Single period specifications yielded measures of $\alpha$ that were in the neighborhood of 0.5 and easily statistically

11 With a sample size of only 28 provinces (Ostans) in a year, small sample size is a significant problem. 12 See Appendix E of Greene (2003) for a discussion of optimization algorithms. 
greater than zero in accordance with theory. Measures of $\beta$ were generally in the 0.01 to 0.04 inverse kilometer range, and also significantly greater than 0 . The parameter $\beta$ can be interpreted as the drop off in economic relationships. Our values in the range of 0.01 to 0.04 indicate that economic interaction drops by approximately two thirds for every 25 to $100 \mathrm{~km}$ separating two Ostans. Of course, for $\beta$ much larger than our values, the market potential function drops to zero too quickly. Therefore, our values of $\beta$ appear to be reasonable. The extreme HAS specification had a harder time fitting the model, though when NLS did converge its results were similar to those of simple distance and standard HAS. Generally, using all provinces and dropping Tehran and Khuzestan, as the highest GRDPs with a significant gap to the rest of the provinces, made little difference. This indicates that the extreme observations associated with the largest centers are not affecting parameter estimates.

The time differenced MPF model performed reasonably well, but was sometimes unable to converge due to limited information. This result is quite intuitive and appealing. By differencing between some sets of years, too much information was lost and convergence was unattainable. ${ }^{13}$ However when convergence was achieved, parameter estimates were more accurate than the single period estimates, suggesting that differencing was a successful control. The time differenced MPF model produced $\alpha$ estimates that were generally around 1.0, while the $\beta$ estimates were broadly similar to those of the single period model.

Throughout our MPF analysis, there was no reason to question the underlying MPF model's applicability. In general, our estimates are roughly similar to those of the many MPF studies quoted in Garcia Pires (Garcia Pires, 2006), though we generally estimate higher $\alpha$ values and will discuss this in more detail in the conclusion.

13 In particular, between years of 1381 and 1382, no version of any MPF model converged. 
The single period Krugman (Table 4) converged less successfully than the single period MPF, though it was somewhat better when omitting Tehran and Khuzestan. This suggests that influential observations of these provinces had a larger effect on the structural parameters of the Krugman model. Parameter estimates for $\mu$ were either implausibly high or outside of allowed theoretical ranges, suggesting that the Krugman model does not describe the data perfectly. ${ }^{14}$ When the regressions did converge, they tended to find $\sigma$ around 7 and $\tau$ roughly between .008 and .015 with reasonable consistency. Since $\mu$ was not estimated accurately, it is not possible to accurately discuss the estimates of $\sigma(1-\mu)$. Note that this is a common problem throughout the empirical literature; it has been difficult to estimate $\mu$ accurately in other papers as well. ${ }^{15}$ The estimates of $\sigma /(\sigma-1)$ were around 1.15 , and statistically greater than 1 , implying increasing returns to scale for Iranian manufacturing. Our estimates were a little lower than those reported in Garcia Pires (Garcia Pires, 2006), suggesting that returns to scale might be smaller in Iran than the western countries surveyed (Table 5). Though simple distance and HAS measurements were reasonably successful, the extreme HAS specification fit the data poorly.

The differenced Krugman model also had estimated parameters less accurately than the single period analog. This could be expected, again, due to the informational cost of differencing. When the estimates converge the time differenced model yields estimates of $\sigma$ that are around 3, which is significantly lower than in the single period model. The differenced Krugman model could not estimate $\tau$ very accurately, particularly in the model variations that exclude Tehran and Khuzestan. When estimated significantly, $\tau$ ranges from .003 to .04. Since $\sigma$ is lower in the differenced model, $\sigma /(\sigma-1)$ is correspondingly higher, ranging from 1.3 to 1.5 , though often

14 If $1-\mu$ is interpreted as the fraction of income spent on homogeneous food products grown by peasants, Iranians likely spend significantly more than the few percent estimated when $\mu$ is estimated to lie inside the allowable region.

15 See table of literature estimates in (Garcia Pires, 2006). 
estimated with less precision. Again, the extreme HAS model performs less well, though the difference is not as stark as in other model versions.

Our estimates of parameters in the Krugman and MPF models tend to be significant, particularly when not considering the extreme HAS distance versions. They are broadly qualitatively similar to the estimates of (Garcia Pires, 2006) for Spain and (Hanson, 2005) for the United States, though with some differences which could point to differences between Iran and the other western countries.

\section{Conclusions}

Data from the provinces of Iran showed generally good fit to both models as discussed above, and satisfied both MPF and Krugman models' specifications. This could be interpreted to mean that the provinces of Iran are generally subject to notions of 'New Economic Geography' and exhibit spatial wage structure. Since the theoretical models hold, wages in a province do seem to be endogenously determined by workers choosing to move in order to maximize their effective wage. Distance also seems to affect wages, as they tend to be higher in regions closer to larger markets. In general, our results confirm Harris (1954) market potential hypothesis and similar studies, since in the Iranian provinces nominal wages are positively correlated with the distance-weighted sum of personal income in surrounding regions.

Based on this fit of Iranian data to the NEG model, agglomeration of Iranian industry is promoted when economies of scale are strong, trade costs are low, and people spend a large portion of their income on manufactured goods. The economies of scale encourage Iranian firms to concentrate production in a few central city locations in order to exploit scale gains. Low trade and transportation costs allow firms to serve remote markets from central locations while demand patterns biased for industrial goods support larger agglomerations of firms. 
Also as mentioned earlier, in comparing our three different approaches to measuring distance, the Extreme HAS approach was much less able to converge which might suggest that Tehran does not act as a universal hub for Iran. The convergence of the other two approaches was successful and close in the results, which might suggest that trade in Iran, happens in both patterns. However, $\sigma$ did not show significant differences between three approaches which might suggest we cannot make a conclusive statement in comparing the three patterns.

Another finding was that the estimates of $\sigma /(\sigma-1)$ were lower than those reported in other NEG empirical literature (Table 5), suggesting that returns to scale might be smaller in Iran than the western countries surveyed. This might be a result of the nature of the technologies used in the nonfarm private sector in Iran, which is potentially less industrial and more traditional. This would suggest that by dispersion and decentralization of industry Iran would have a level of loss due to a reduction in economy of scale but such loss would be potentially less than the loss that western countries would face through similar policies. It could be said that if Iran wants to decentralize its industry, it would be better off to do so while the nature of its industry allows for less loss. However, it should be noted that the Krugman model is a static model, and when talking about policies a dynamic view would be more accurate.

We also found significantly and consistently higher $\alpha$ values in comparison to similar analyses of other countries (Table 5). Since $\alpha$ can be interpreted as the size of the effect of market potential on wages, our estimates suggest that Iranian wage levels are more strongly related to geographic market potential. Since the countries that are cited in this paper are rich, developed countries (US, Japan, Germany, Spain, Italy, and Belgium), this is an intriguing result.

One possible interpretation of this might be to suggest that Iran has a more distancesensitive trade structure than those other countries. The distance sensitivity might be a result of 
several factors. First, the transportation system between provinces in Iran may be less developed than in those other countries, which enhances the effect of distance on trade. Second, Iran is a highly mountainous country with a very diverse geography. This might have direct effect on the development of transportation systems between provinces.

The overall result of this study corroborates the notion of centralization in the Iranian economy. Industry, trade, and workers all have incentives to agglomerate in larger cities and especially in Tehran to benefit from economies of scale in the form of higher wages and profits. The large wage variations explained by economic geography could cause significant internal migration, beyond that seen in western countries. Indeed, significant internal migration has been observed in Iran in past years.

The size of the effect of market potential on wages in Iran confirms the need for improvement in the transportation sector between provinces. By improving transportation, it is possible to decrease the effective distances across Iran. To the extent that lower effective distance decreases the effects of economic geography, improved transportation could serve to equalize wages throughout the country \& decrease incentives for destabilizing internal migration.

\section{Acknowledgements:}

The author is grateful to William Dickens, Anton Dobronogov, Armando Pires, Carol Graham, Randi Hjalmarsson, and Thomas Schelling for helpful discussion and comments, and to Jeffrey Borowitz for the data analysis support during the preparation of this work. Thanks also to Jim Bitgood, Pooneh Farmanesh, Nancy Gallagher, Heidi von Geldern, Francesca Perry, and John Rust for supporting this research, and to the 'Iran National Cartographic Center' and the 'Statistical Center of Iran' for making their data publicly available. This research was conducted at the University of Maryland as a Ph.D. candidate in Policy Studies-International Development and was sponsored by the World Bank, Middle East and North Africa Region, Social and Economic Development Group. The usual disclaimer applies. 


\section{References}

Axtell, R. L. (2001). Zipf Distribution of U.S. Firm Sizes. Science, 293(5536), 1818-1820.

Brakman, S., Garretsen, H., \& Schramm, M. (2004). The spatial distribution of wages: estimating the Helpman-Hanson model for Germany. Journal of Regional Science, 44(3), 437-466.

De Bruyne, K. (2002). The Location of Economic Activity. Is There a Spatial Employment Structure in Belgium? Katholiek University of Leuven.

Eaton, J., \& Kortum, S. (1999). International technology diffusion: theory and measurement. International Economic Review, 40, 537-570.

Eaton, J., \& Kortum, S. (2002). Technology, geography, and trade. Econometrica, 70, 1741- 1779.

Fujita, M., Krugman, P., \& Venables, A. J. (1999). The Spatial Economy. Cambridge MA: MIT Press.

Garcia Pires, A. J. (2006). Estimating Krugman's economic geography model for the Spanish regions. Spanish Economic Review, 2006(8), 83-112.

Greene, W. (2003). Econometric Analysis. Upper Saddle River: Pearson Education Inc.

Hanson, G. H. (1998). Market potential, increasing returns, and geographic concentration. National Bureau of Economic Research.

Hanson, G. H. (2005). Market potential, increasing returns, and geographic concentration. Journal of International Economics, 67, 1-24.

Harris, C. (1954). The Market as a factor in the localization of production. Annals of the Association of American Geographers, 44, 315-348.

Head, K., \& Mayer, T. (2004). The Empirics of Agglomeration and Trade. In J. Henderson \& J. F. Thisse (Eds.), Handbook of Regional and Urban Economics (Vol. 4). New York: North Holland.

Helpman, E. (1998). The size of regions. In D. Pines, E. Sadka \& J. Zilcha (Eds.), Topics in public economics: theoretical and applied analysis. Cambridge: Cambridge University Press.

Hummels, D. (1999). Towards a geography of trade costs. University of Chicago.

Krugman, P. (1980). Scale economies, product differentiation, and the pattern of trade. American Economic Review, 70, 950- 959.

Krugman, P. (1991). Increasing returns and economic geography. Journal of Political Economy, 99, 483499.

Krugman, P. (1993). On the number and location of cities. European Economic Review, 37, 293-298. 
Limao, N., \& Venables, A. J. (2001). Infrastructure, geographical disadvantage, transport costs, and trade. World Bank Economic Review, 15, 451- 479.

Mion, G. (2004). Spatial externalities and empirical analysis: the case of Italy. Journal of Urban Economics, 56, 97-118.

Neary, J. P. (2001). Of Hype and Hyperbolas: Introducing the New Economic Geography. Journal of Economic Literature, 34, 536-561.

Overman, H. G., Redding, S., \& Venables, A. J. (2003). The Economic Geography of Trade, Production, and Income: A Survey of Empirics. In E. K. Choi \& J. Harrigan (Eds.), Handbook of International Trade (pp. 353-387). Malden: Blackwell.

Paluzie Hernandez, E., Pons Novell, J., \& Tirado Fabregat, D. A. (2005). Potencial de Mercado y Estructura Espacial de los Salarios en las Regiones Espaolas, 1955-1995. Cuadernos Aragoneses de Economía, 15(1), 17-37.

Puga, D. (1999). The rise and fall of regional inequalities. European Economic Review, 43, 303-334.

Redding, S., \& Venables, A. J. (2004). Economic geography and international inequality. Journal of International Economics, 62, 53-82.

Roback, J. (1982). Wages, rents, and the quality of life. Journal of Political Economy, 90, 1257-1278.

Roos, M. (2001). Wages and market potential in Germany. Jahrb Regional wissensch, 21, 171-195.

Wooldridge, J. M. (2003). Introductory econometrics: A modern approach (2nd ed.). Mason, OH: SouthWestern Publishing. 


\section{Appendixes}

List of Tables

Table 1.

GRDP and population data of Iranian provinces for years of 1379, 1380, 1381, and 1382

\begin{tabular}{|c|c|c|c|c|c|c|c|c|c|c|c|c|}
\hline & \multicolumn{4}{|c|}{ GDP at market prices } & \multicolumn{4}{|c|}{ Contribution to GDP } & \multicolumn{4}{|c|}{ Share of total population } \\
\hline & 1382 & 1381 & 1380 & 1379 & 1382 & 1381 & 1380 & 1379 & 1382 & 1381 & 1380 & 1379 \\
\hline Country total & 1198390 & 986269 & 745536 & 645256 & 100 & 100 & 100 & 100 & 100 & 100 & 100 & 100 \\
\hline Tehran & 309426 & 255350 & 193374 & 155793 & 25.8 & 25.9 & 26 & 24.14 & 17.6 & 17.8 & 17.8 & 17.66 \\
\hline hu & 161069 & 140840 & 96451 & 90133 & 13.4 & 14.3 & 13 & 13.97 & 3 & & 8 & .66 \\
\hline Esfahan & 75051 & 57653 & 45409 & 40195 & 6.3 & 5.8 & 6.1 & 6.23 & 6.5 & 6.6 & 6.6 & 6.55 \\
\hline Khor & 73330 & 59928 & 47252 & 40238 & b & 6. & 6.3 & 6.2 & 9.6 & 2 & 4 & 9.6 \\
\hline Fars & 6 & & & 27371 & 5 & 4.4 & 4.3 & 4.24 & 4 & & 3 & .33 \\
\hline E. Aza & 45691 & 39378 & 30287 & 26363 & 3.8 & 4 & 4.1 & 4.09 & 5.2 & 5.2 & 5.2 & 5.28 \\
\hline Maz & 33 & 35323 & 27541 & 22336 & 3.6 & 3.6 & 3.7 & 3.46 & 4.2 & 1.2 & 4.2 & .24 \\
\hline Koh & 41546 & 36835 & 30731 & 32595 & 3.5 & 3.7 & 4.1 & 5.05 & 1 & 1 & 1 & 0.94 \\
\hline Bus & 459 & 15039 & 501 & 7079 & 3 & 1.5 & 1.3 & 1.1 & 1.2 & 1.2 & .2 & 1.23 \\
\hline Ker & 679 & & & 21011 & .5 & 6 & 2.7 & 3.26 & & .4 & & .36 \\
\hline Gilan & 28078 & 23778 & 18548 & 16080 & 2.3 & 2.4 & 2.5 & 2.49 & 3.6 & 3.5 & 3.6 & 3.59 \\
\hline Mar & 152 & & & 14725 & & 2.4 & 2.6 & 2.28 & 2 & 2 & 2 & \\
\hline W. A & 24645 & 20453 & 16243 & 14495 & 2 & 2.1 & 2.2 & 2.25 & 4.3 & 4.2 & 4.2 & 4.21 \\
\hline Horr & 21970 & 17642 & 14630 & 11712 & 1.8 & 1.8 & 2 & 1.82 & 1.9 & 1.9 & 1.9 & 1.85 \\
\hline Ker & 792 & & 10721 & 9000 & & & 1.4 & 1.39 & 2.9 & 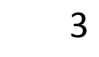 & 3 & 2.99 \\
\hline Han & 131 & 15800 & 11543 & 9364 & 1.5 & 1.6 & 1.6 & 1.45 & 2.6 & 2.6 & 2.7 & 2.68 \\
\hline Qazı & 261 & 14216 & 12339 & 10558 & 1.4 & 1.4 & 1.7 & 1.64 & 1.7 & 1.6 & .6 & 1.62 \\
\hline & & & & 9377 & & & 1.4 & 1.45 & 2.4 & & & 2.38 \\
\hline Lores & 274 & 12551 & 10466 & 8886 & 1.3 & 1.3 & 1.4 & 1.38 & 2.6 & 2.6 & .6 & 2.58 \\
\hline Yazd & & & 9511 & 7545 & 1 & 1.2 & 1.3 & 1.17 & 1.4 & 1.4 & 3 & 1.27 \\
\hline Sistar & 91 & 11073 & 8740 & 7295 & 1.1 & 1.1 & 1.2 & 1.13 & 3.2 & 3.2 & .1 & 3.08 \\
\hline Arde & 492 & 10246 & 7884 & 6879 & 1 & 1 & 1.1 & 1.07 & .9 & 8 & 9 & 1.87 \\
\hline Qom & 779 & 10083 & 8136 & 6766 & 1 & 1 & 1.1 & 1.05 & 1.5 & 1.5 & 5 & 1.46 \\
\hline Koro & 118 & 9853 & 7203 & 6414 & + & 1 & 1 & 0.99 & 2.3 & 2.3 & .3 & 2.27 \\
\hline Zanj & 10532 & 8279 & 6315 & 5900 & 0.9 & 0.8 & 0.9 & 0.91 & 1.4 & 1.4 & 1.4 & 1.45 \\
\hline Semnan & 9211 & 7187 & 5800 & 4819 & 0.8 & 0.7 & 0.8 & 0.75 & 0.9 & 0.9 & 0.9 & 0.85 \\
\hline Chaharmaha & 7694 & 6184 & 4985 & 4066 & 0.6 & 0.6 & 0.7 & 0.63 & 1.2 & 1.2 & 1.2 & 1.23 \\
\hline Ilam & 6294 & 7849 & 5667 & 3967 & 0.5 & 0.8 & 0.8 & 0.61 & 0.8 & 0.8 & 0.8 & 0.83 \\
\hline Supraregion & 42457 & 38123 & 24087 & 24297 & 3.5 & 3.9 & 3.2 & 3.77 & 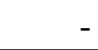 & 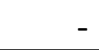 & & \\
\hline
\end{tabular}


Table 2.

Hubs and Spokes in HAS distance analysis

\begin{tabular}{l|l} 
Hub & Spoke \\
\hline Tehran & Tehran \\
Mazandaran & Gilan \\
& Semnan \\
& Qom \\
& Markazi \\
& Hamadan \\
& Qazvin \\
& Zanjan \\
\hline Esfahan & Esfahan \\
& Yazd \\
& Chaharmahal Bakhtiyari \\
& Lorestan \\
& Kermanshah \\
& Ilam \\
\hline East Azarbayejan & East Azarbayejan \\
& West Azarbayejan \\
Ardebil \\
Kordestan \\
\hline Khorasan & Fars \\
Bushehr \\
Khuzestan \\
Kohgiluyeh \& Boyerahmad \\
Kerman \\
Hormozgan \\
Sistan \& Baluchestan \\
\hline Khorasan \\
Golestan \\
\hline
\end{tabular}


Table 3.

Market Potential Function results, 26 Provinces

\begin{tabular}{|c|c|c|c|c|}
\hline \multirow[b]{2}{*}{ MPF } & \multicolumn{4}{|c|}{ Simple distance analysis } \\
\hline & 1379 & 1380 & 1381 & 1382 \\
\hline \multirow[t]{2}{*}{$\bar{\theta}$} & $-6.1657^{*}$ & $-7.0666^{*}$ & $-5.1328^{*}$ & $-8.0743^{*}$ \\
\hline & (1.9725) & (1.9718) & (1.5706) & (2.4129) \\
\hline \multirow[t]{2}{*}{$\alpha$} & $0.51312 *$ & $0.56285^{*}$ & $0.4545^{*}$ & $0.61997^{*}$ \\
\hline & (0.1143) & (0.1161) & (0.0931) & (0.1386) \\
\hline \multirow[t]{2}{*}{$\beta$} & 0.0156 & 0.0219 & 0.0373 & $0.0127^{*}$ \\
\hline & $(0.0084)$ & $(0.0121)$ & $(0.0455)$ & $(0.0047)$ \\
\hline \multirow[t]{2}{*}{$\mathrm{R}^{2}$} & 0.4558 & 0.5061 & 0.5438 & 0.5253 \\
\hline & \multicolumn{4}{|c|}{ HAS distance analysis } \\
\hline \multirow[t]{2}{*}{$\theta$} & $-5.4658 *$ & $-7.2889 *$ & $-5.5173^{*}$ & $-6.2672 *$ \\
\hline & $(1.8272)$ & $(1.8964)$ & $(1.5209)$ & $(1.7947)$ \\
\hline \multirow[t]{2}{*}{$\alpha$} & $0.47538 *$ & $0.57347^{*}$ & $0.47748 *$ & $0.51988^{*}$ \\
\hline & $(0.1082)$ & $(0.1113)$ & $(0.0905)$ & $(0.1074)$ \\
\hline \multirow[t]{2}{*}{$\beta$} & 0.0204 & 0.0103 & 0.0374 & 0.0213 \\
\hline & $(0.0166)$ & $(0.0054)$ & $(0.0427)$ & $(0.0179)$ \\
\hline \multirow[t]{2}{*}{$\mathrm{R}^{2}$} & 0.4462 & 0.5146 & 0.5454 & 0.4853 \\
\hline & \multicolumn{4}{|c|}{ Extreme HAS distance analysis } \\
\hline \multirow[t]{2}{*}{$\theta$} & -1.1102 & $-6.641^{*}$ & $-5.6083^{*}$ & $-7.418^{*}$ \\
\hline & $(29.5740)$ & $(2.0246)$ & $(1.5794)$ & $(2.2746)$ \\
\hline \multirow[t]{2}{*}{$\alpha$} & 0.1469 & $0.5382^{*}$ & $0.48278 *$ & $0.58236^{*}$ \\
\hline & (1.4541) & $(0.1190)$ & $(0.0933)$ & $(0.1316)$ \\
\hline \multirow[t]{2}{*}{$\beta$} & -0.0025 & 0.0088 & 0.0122 & $0.00574 *$ \\
\hline & $(0.0237)$ & $(0.0051)$ & $(0.0150)$ & $(0.0017)$ \\
\hline $\mathrm{R}^{2}$ & 0.0322 & 0.4944 & 0.5447 & 0.5069 \\
\hline
\end{tabular}

Standard errors are in parentheses.

* shows statistical significance.

Table 4.

Krugman results, 26 Provinces 


\begin{tabular}{|c|c|c|c|c|}
\hline \multirow[b]{2}{*}{ Krugman } & \multicolumn{4}{|c|}{ Simple distance analysis } \\
\hline & 1379 & 1380 & 1381 & 1382 \\
\hline \multirow[t]{2}{*}{$\theta$} & $-1.9882^{*}$ & $-2.0832^{*}$ & $-2.1727^{*}$ & $-2.0979 *$ \\
\hline & $(0.3958)$ & $(0.4157)$ & $(0.4413)$ & $(0.4475)$ \\
\hline \multirow[t]{2}{*}{$\sigma$} & $7.3263^{*}$ & $7.0287^{*}$ & $6.558^{*}$ & $6.9719 *$ \\
\hline & $(1.4427)$ & $(1.3914)$ & (1.2910) & $(1.4600)$ \\
\hline \multirow[t]{2}{*}{$\mu$} & $0.98121 *$ & 0.97999* & $1.0061^{*}$ & $0.97469 *$ \\
\hline & $(0.0318)$ & $(0.0310)$ & $(0.0387)$ & $(0.0350)$ \\
\hline \multirow[t]{2}{*}{$\mathrm{T}$} & $0.0167^{*}$ & $0.0165^{*}$ & $0.00888 *$ & $0.00846^{*}$ \\
\hline & $(0.0093)$ & $(0.0035)$ & $(0.0011)$ & $(0.0010)$ \\
\hline \multirow[t]{2}{*}{$\sigma /(\sigma-1)$} & $1.1581^{*}$ & $1.1659 *$ & $1.1799 *$ & $1.1675^{*}$ \\
\hline & $(0.0360)$ & $(0.0383)$ & $(0.0418)$ & $(0.0409)$ \\
\hline \multirow[t]{2}{*}{$\sigma(1-\mu)$} & 0.1376 & 0.1407 & -0.0402 & 0.1765 \\
\hline & $(0.2317)$ & $(0.2165)$ & $(0.2543)$ & $(0.2408)$ \\
\hline \multirow[t]{2}{*}{$\mathrm{R}^{2}$} & 0.9793 & 0.9820 & 0.9776 & 0.9804 \\
\hline & \multicolumn{4}{|c|}{ HAS distance analys is } \\
\hline \multirow[t]{2}{*}{$\theta$} & $-2.0492^{*}$ & $-2.12^{*}$ & $-1.2791^{*}$ & $-2.042^{*}$ \\
\hline & $(0.4002)$ & $(0.4223)$ & $(0.2515)$ & $(0.4152)$ \\
\hline \multirow[t]{2}{*}{$\sigma$} & $7.2286^{*}$ & $6.8749 *$ & $11.274^{*}$ & 7.1036* \\
\hline & $(1.3948)$ & $(1.3531)$ & $(2.2310)$ & $(1.4316)$ \\
\hline \multirow[t]{2}{*}{$\mu$} & $0.97017^{*}$ & $0.98242 *$ & $0.99466 *$ & $0.98189 *$ \\
\hline & $(0.0319)$ & $(0.0292)$ & $(0.0197)$ & $(0.0312)$ \\
\hline \multirow[t]{2}{*}{$T$} & $0.00947 *$ & $0.00947^{*}$ & $0.00754 *$ & $0.00790^{*}$ \\
\hline & $(0.0007)$ & $(0.0018)$ & $(0.0010)$ & $(0.0015)$ \\
\hline \multirow[t]{2}{*}{$\sigma /(\sigma-1)$} & $1.1605^{*}$ & $1.1702^{*}$ & $1.0973 *$ & $1.1638^{*}$ \\
\hline & $(0.0360)$ & $(0.0392)$ & $(0.0211)$ & $(0.0384)$ \\
\hline \multirow[t]{2}{*}{$\sigma(1-\mu)$} & 0.2156 & 0.1208 & 0.0602 & 0.1287 \\
\hline & $(0.2279)$ & $(0.1995)$ & $(0.2228)$ & $(0.2211)$ \\
\hline \multirow[t]{2}{*}{$\mathrm{R}^{2}$} & 0.9807 & 0.9829 & 0.9919 & 0.9811 \\
\hline & \multicolumn{4}{|c|}{ Extreme HAS distance analysis } \\
\hline \multirow[t]{2}{*}{$\theta$} & NC & $-2.1443^{*}$ & $-2.0716^{*}$ & $-2.0224^{*}$ \\
\hline & & $(0.4283)$ & $(0.4169)$ & $(0.4005)$ \\
\hline \multirow[t]{2}{*}{$\sigma$} & NC & $6.9123^{*}$ & $6.7414 *$ & $7.2204^{*}$ \\
\hline & & $(1.3672)$ & $(1.3244)$ & $(1.4196)$ \\
\hline \multirow[t]{2}{*}{$\mu$} & NC & $0.9698^{*}$ & $1.0201 *$ & $0.97608^{*}$ \\
\hline & & $(0.0310)$ & $(0.0388)$ & $(0.0323)$ \\
\hline \multirow[t]{2}{*}{$T$} & NC & $0.00338 *$ & $0.00431 *$ & $0.00445^{*}$ \\
\hline & & $(0.0004)$ & $(0.0011)$ & $(0.0006)$ \\
\hline \multirow[t]{2}{*}{$\sigma /(\sigma-1)$} & NC & $1.1691^{*}$ & $1.1742^{*}$ & $1.1608^{*}$ \\
\hline & & $(0.0391)$ & $(0.0402)$ & $(0.0367)$ \\
\hline \multirow[t]{2}{*}{$\sigma(1-\mu)$} & NC & 0.2088 & -0.1357 & 0.1727 \\
\hline & & $(0.2103)$ & $(0.2602)$ & $(0.2321)$ \\
\hline $\mathrm{R}^{2}$ & & 0.9823 & 0.9764 & 0.9813 \\
\hline
\end{tabular}

Standard errors are in parentheses. * shows statistical significance. 


\section{Table 5.}

Overview of results from similar studies

\begin{tabular}{lllll}
\multicolumn{1}{c}{ Paper } & \multicolumn{1}{c}{ Country } & \multicolumn{1}{c}{$\boldsymbol{\alpha}$} & \multicolumn{1}{c}{$\boldsymbol{\beta}$} & \multicolumn{1}{c}{$\boldsymbol{\sigma} /(\boldsymbol{\sigma}-\mathbf{1})$} \\
\hline Paluzie et al. (2005) & Spain & $0.083^{*}$ to $0.139^{*}$ & $0.077^{*}$ to $0.102^{*}$ & NA \\
Hanson (2005) & USA & $0.24^{*}$ to $0.43^{*}$ & Not Comparable & $1.6^{*}$ to $2.3^{*}$ \\
Brakman et al. (2004) & Germany & $0.049^{*}$ & $0.092^{*}$ & 1.25 to $1.48^{*}$ \\
Roos (2001) & W. Germany & $0.02^{*}$ to $0.08^{*}$ & $0.03^{*}$ to $0.12^{*}$ & 1.19 \\
De Bruyne (2002) & Belgium & $0.26^{*}$ & $0.65^{*}$ & 1.22 \\
Garcia Pires (2006) & Spain & $0.08^{*}$ to $0.24^{*}$ & $0.008^{*}$ to $0.032^{*}$ & $1.23^{*}$ to $1.3^{*}$ \\
\hline This Paper & Iran & $0.48^{*}$ to $0.62^{*}$ & $0.01^{*}$ to $0.02^{*}$ & $1.14^{*}$ to $1.15^{*}$
\end{tabular}




\section{List of Figures}
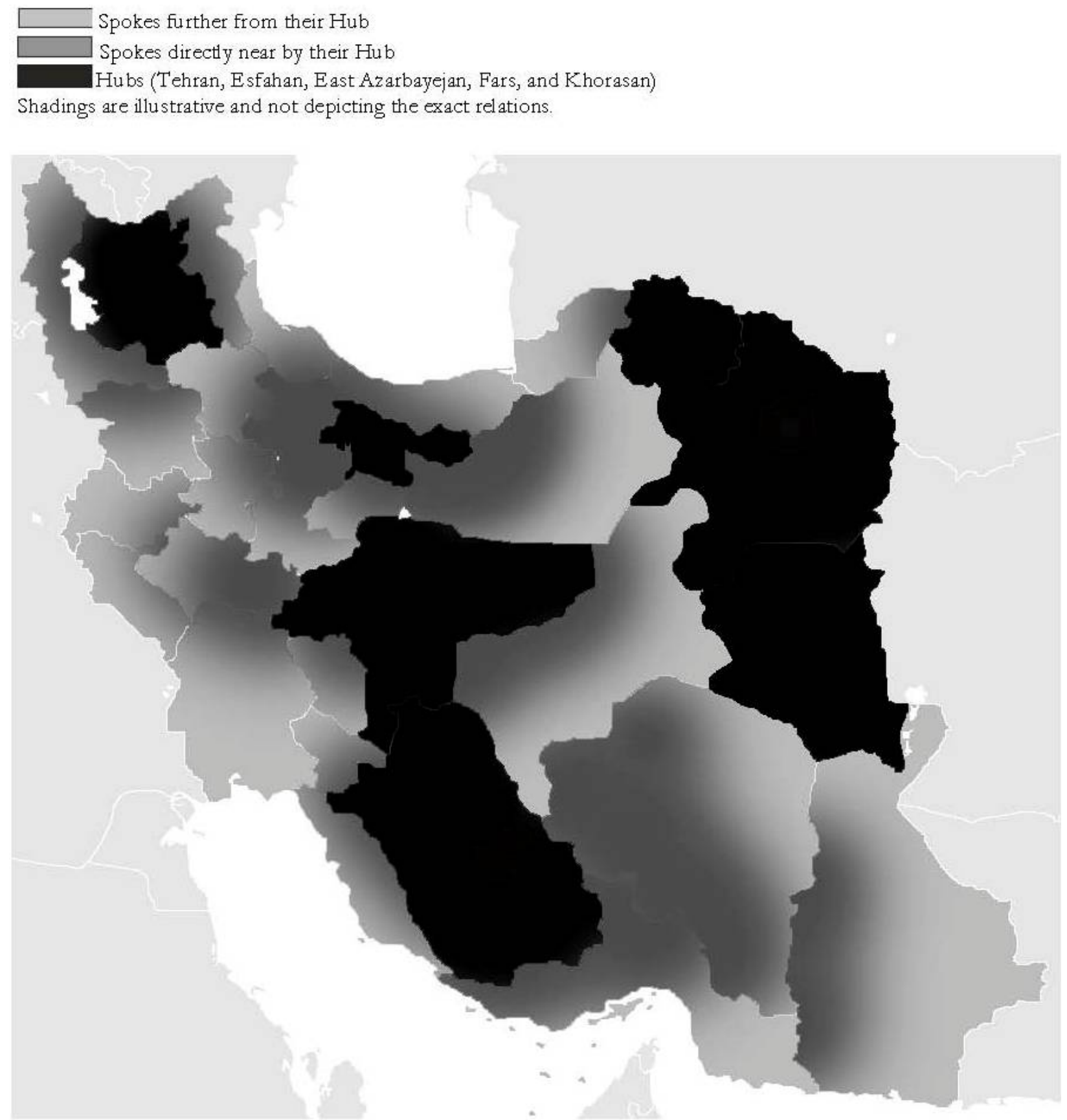

Figure 1. Spatial distribution of Hubs and Spokes in HAS distance analysis 


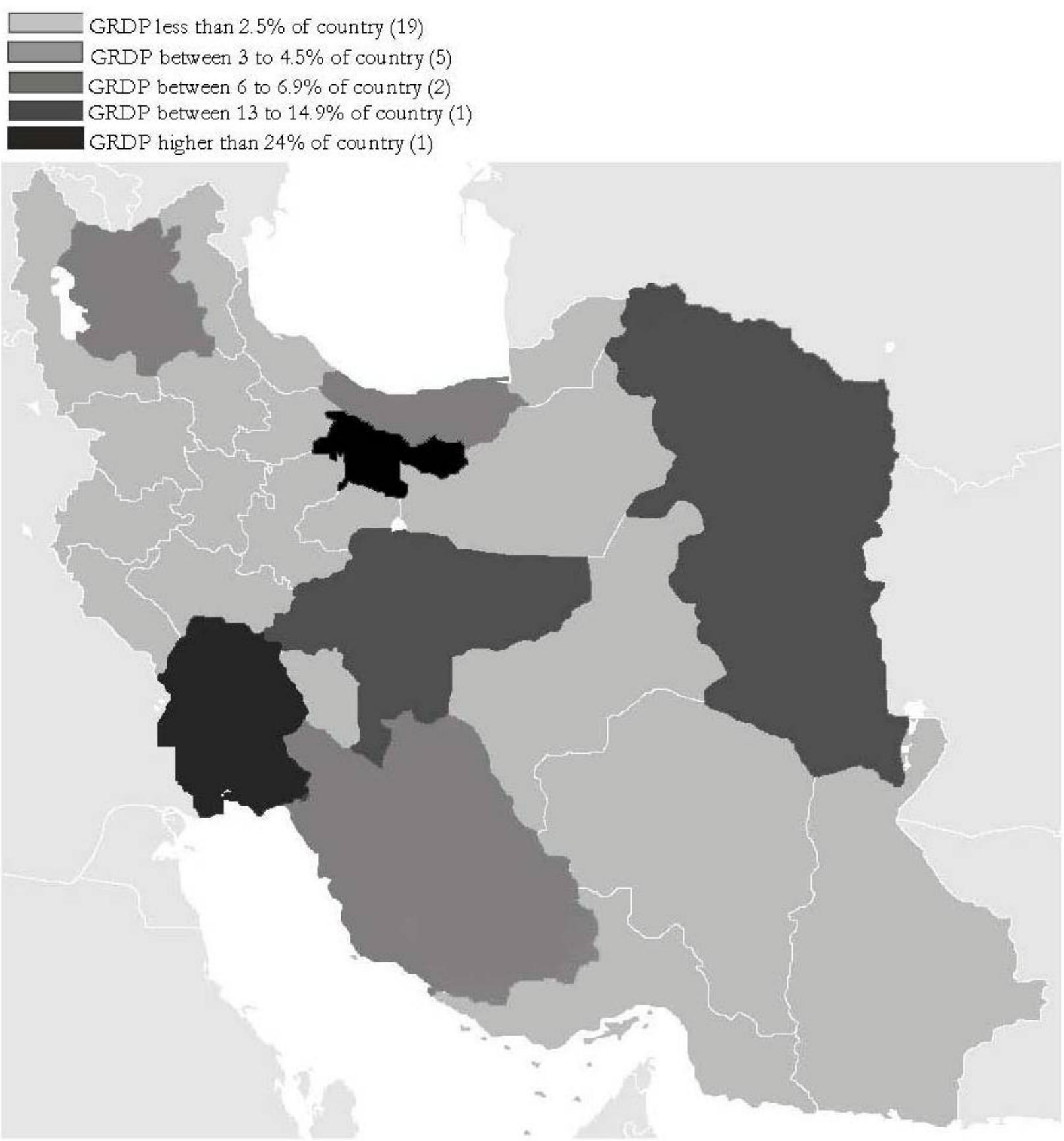

Figure 2. Spatial distribution of GRDPs, all Provinces - 1382 


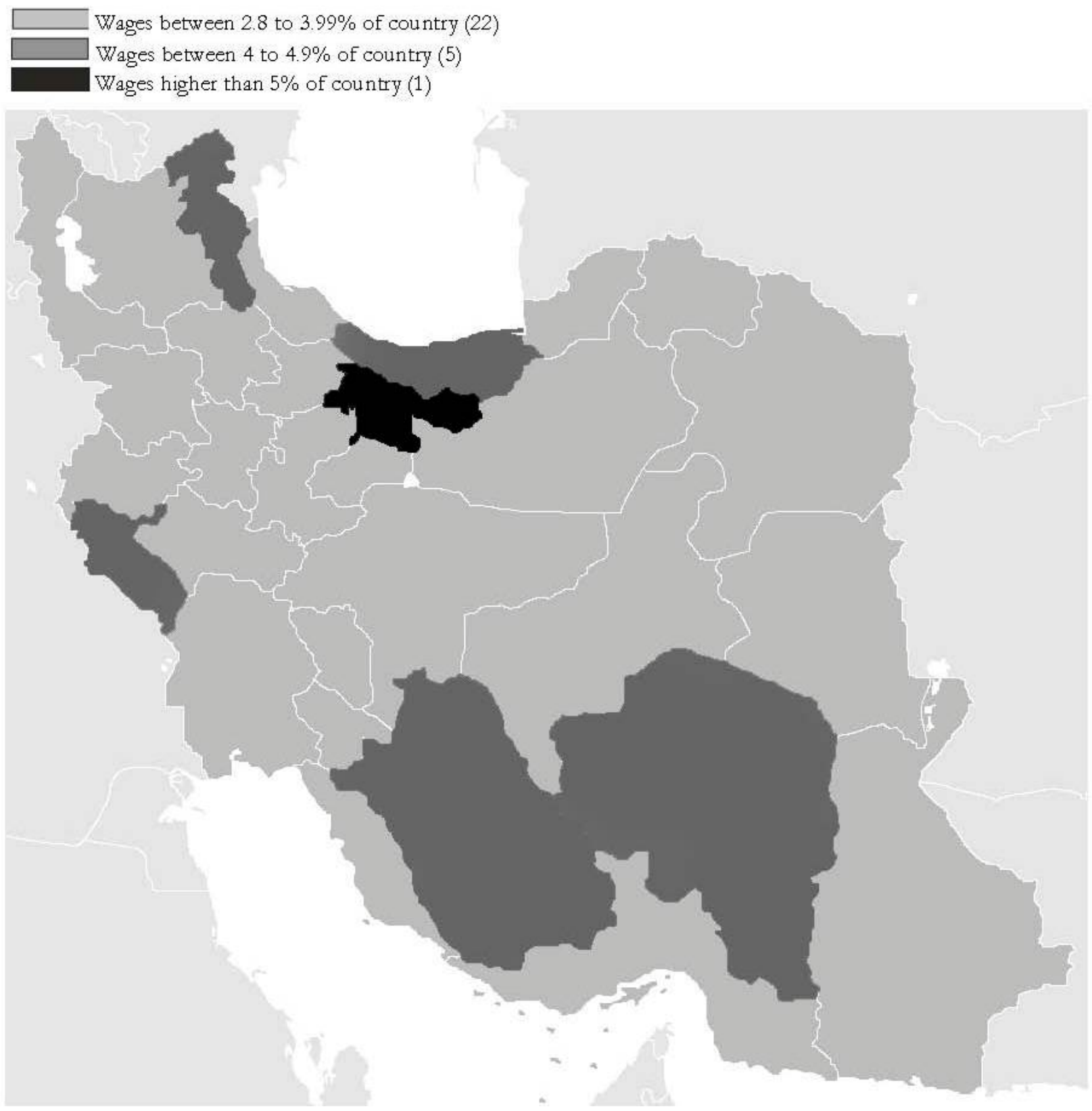

Figure 3. Spatial distribution of Urban W ages, all Provinces - 1382 


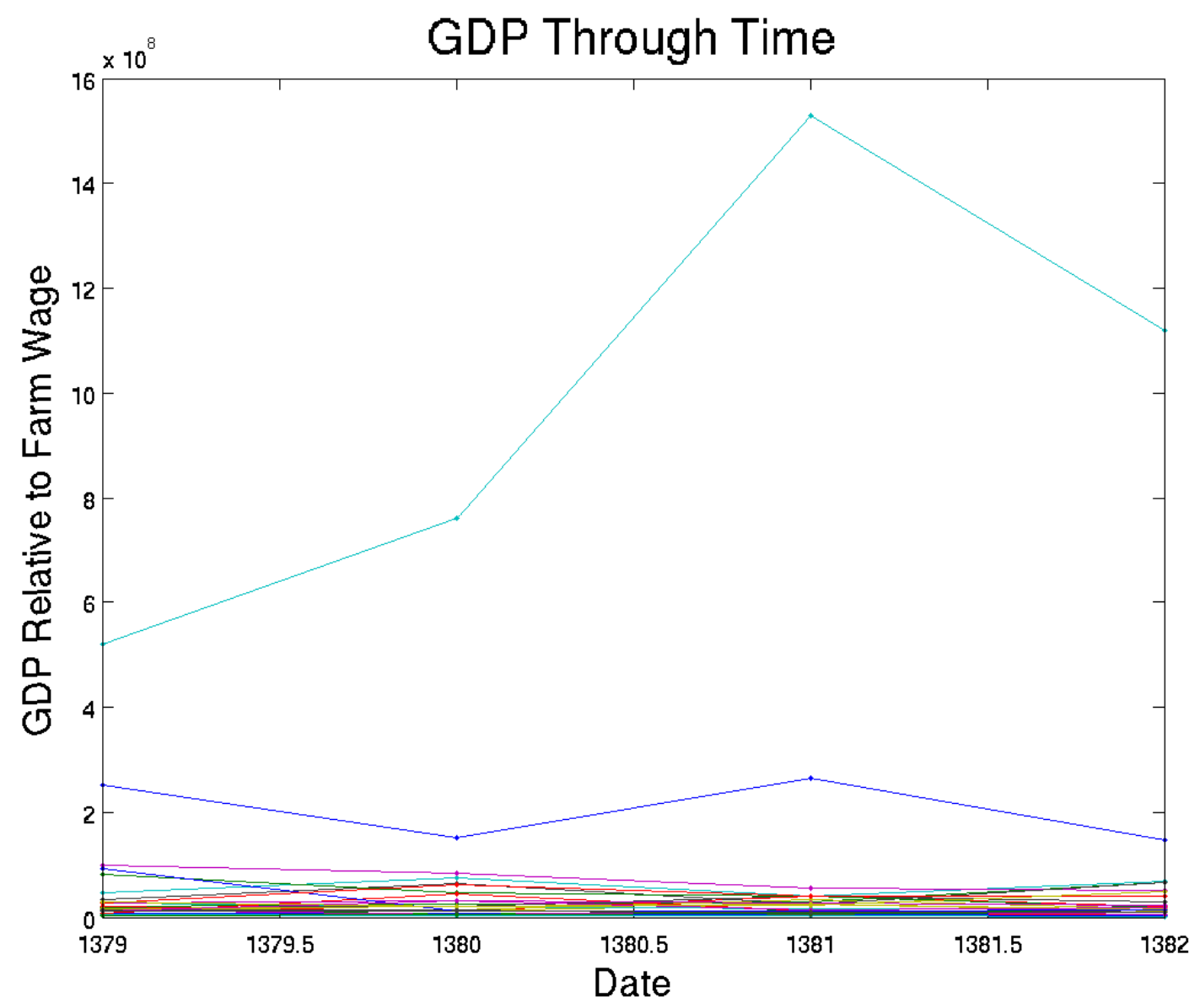

Figure 4. GRDP through time, all Provinces - 1379 to 1382 


\section{GDP Dispersion Analysis}

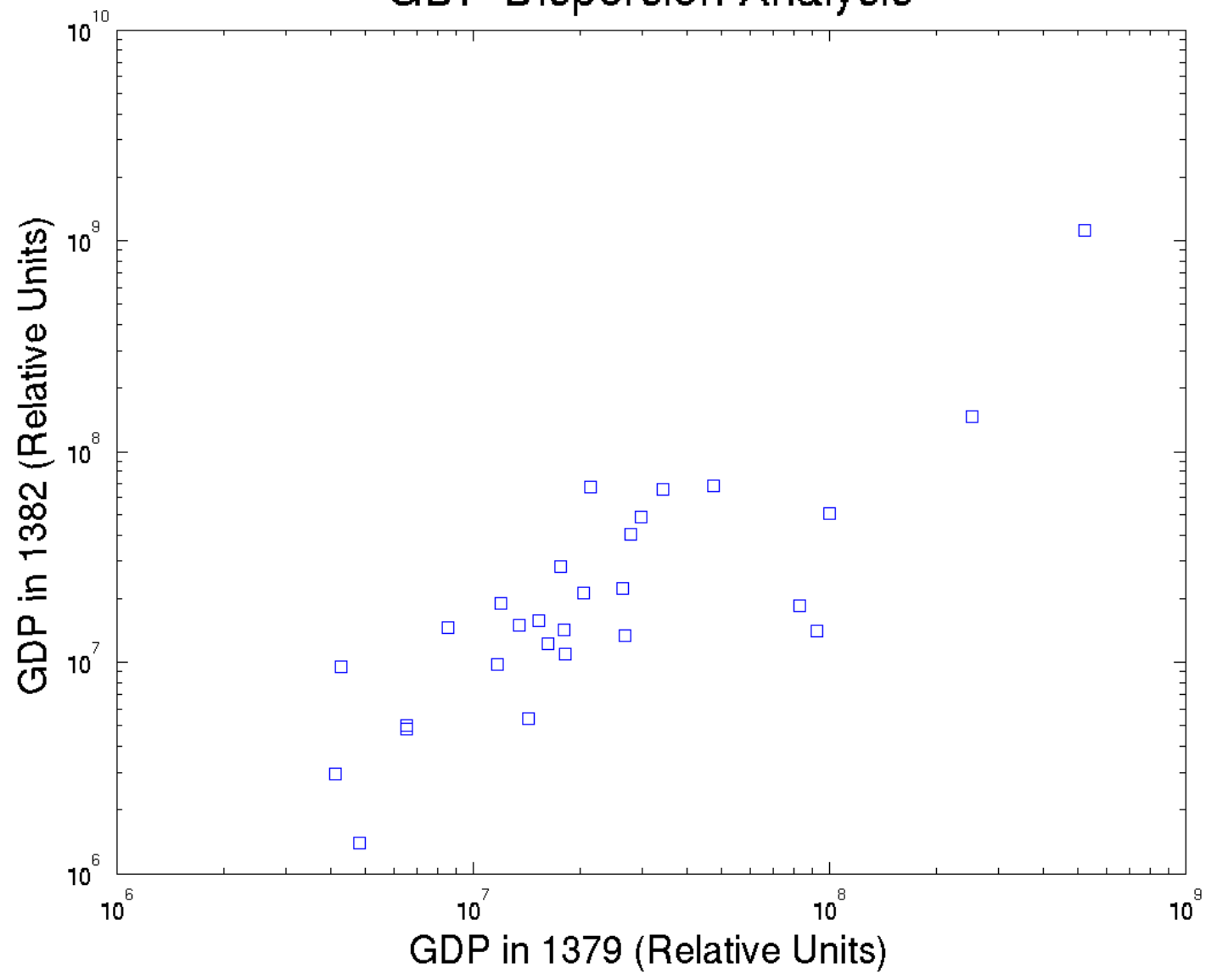

Figure 5. GRDP dispersion analysis - 1382 and 1379 


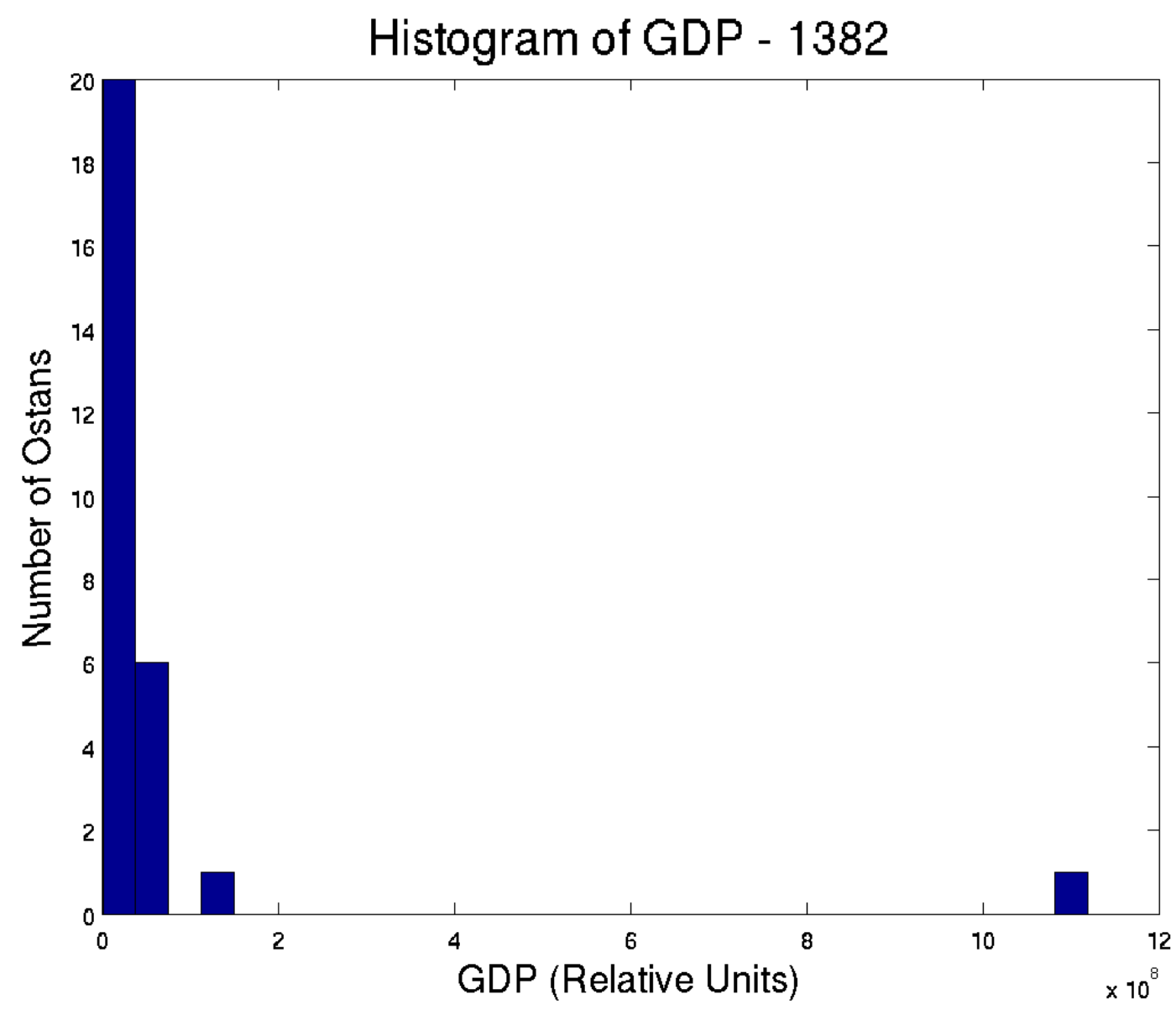

Figure 6. GRDP histogram - 1382 


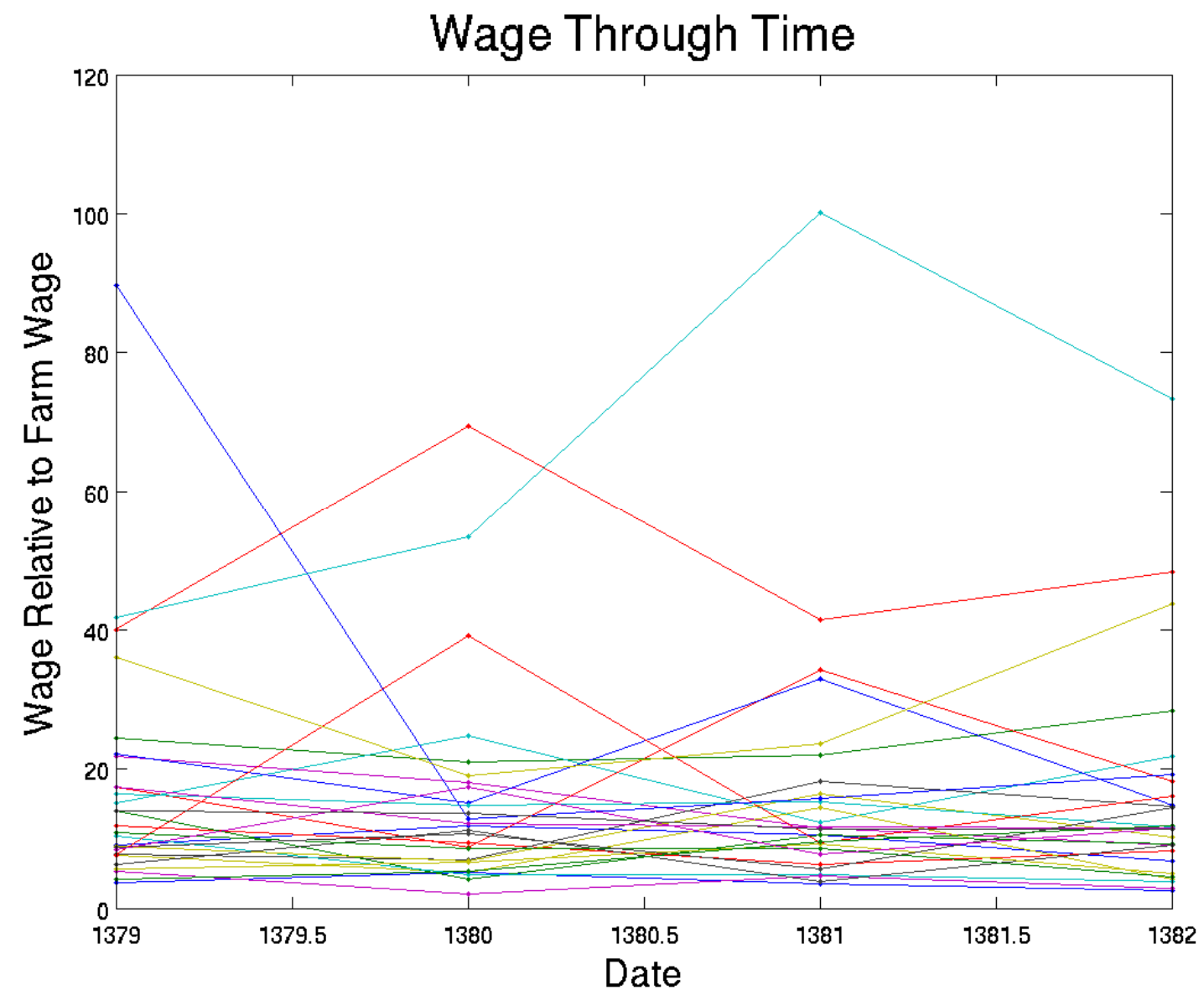

Figure 7. Urban Wage through time, all Provinces - 1379 to 1382 


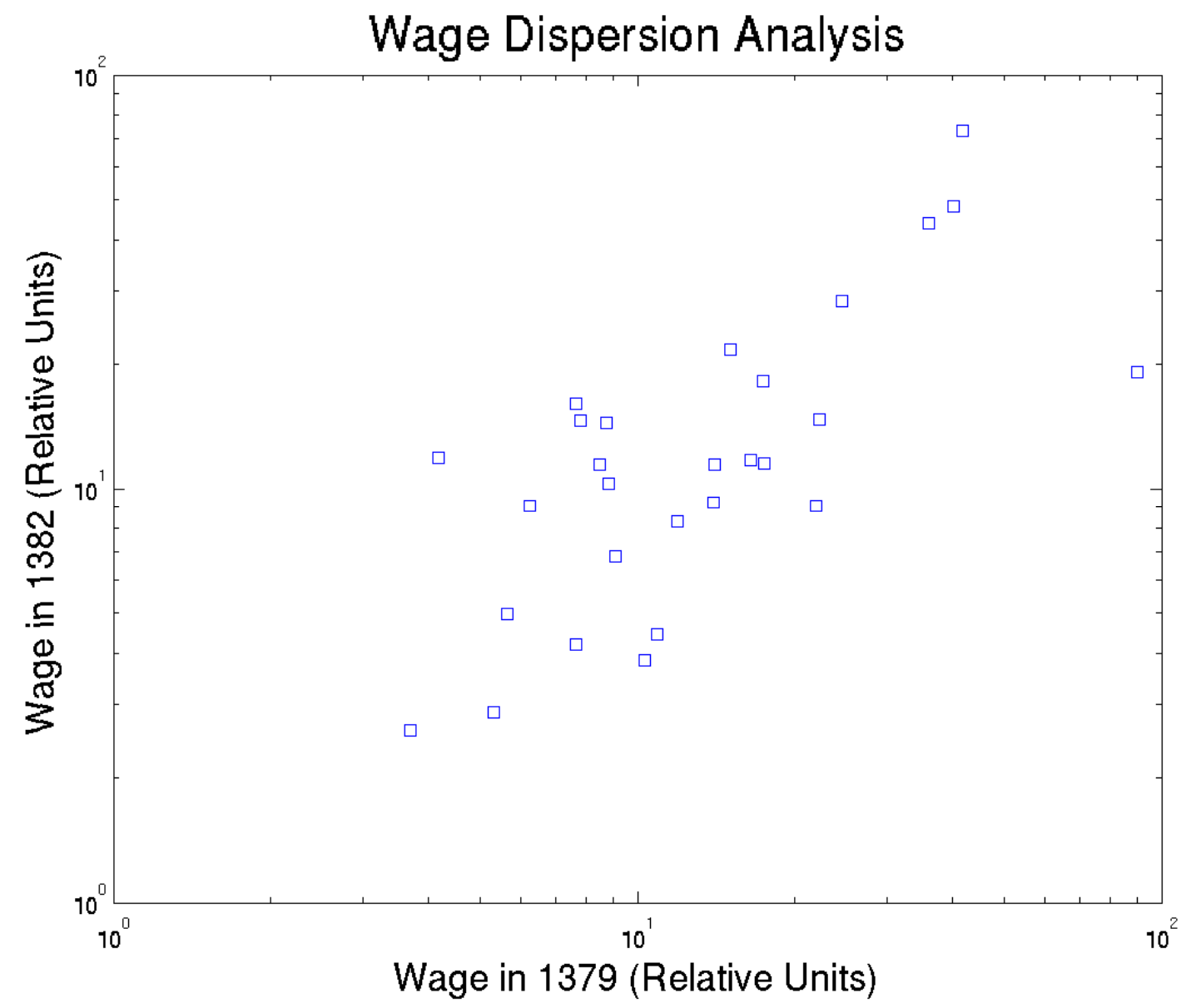

Figure 8. Urban Wage dispersion analysis - 1382 and 1379 


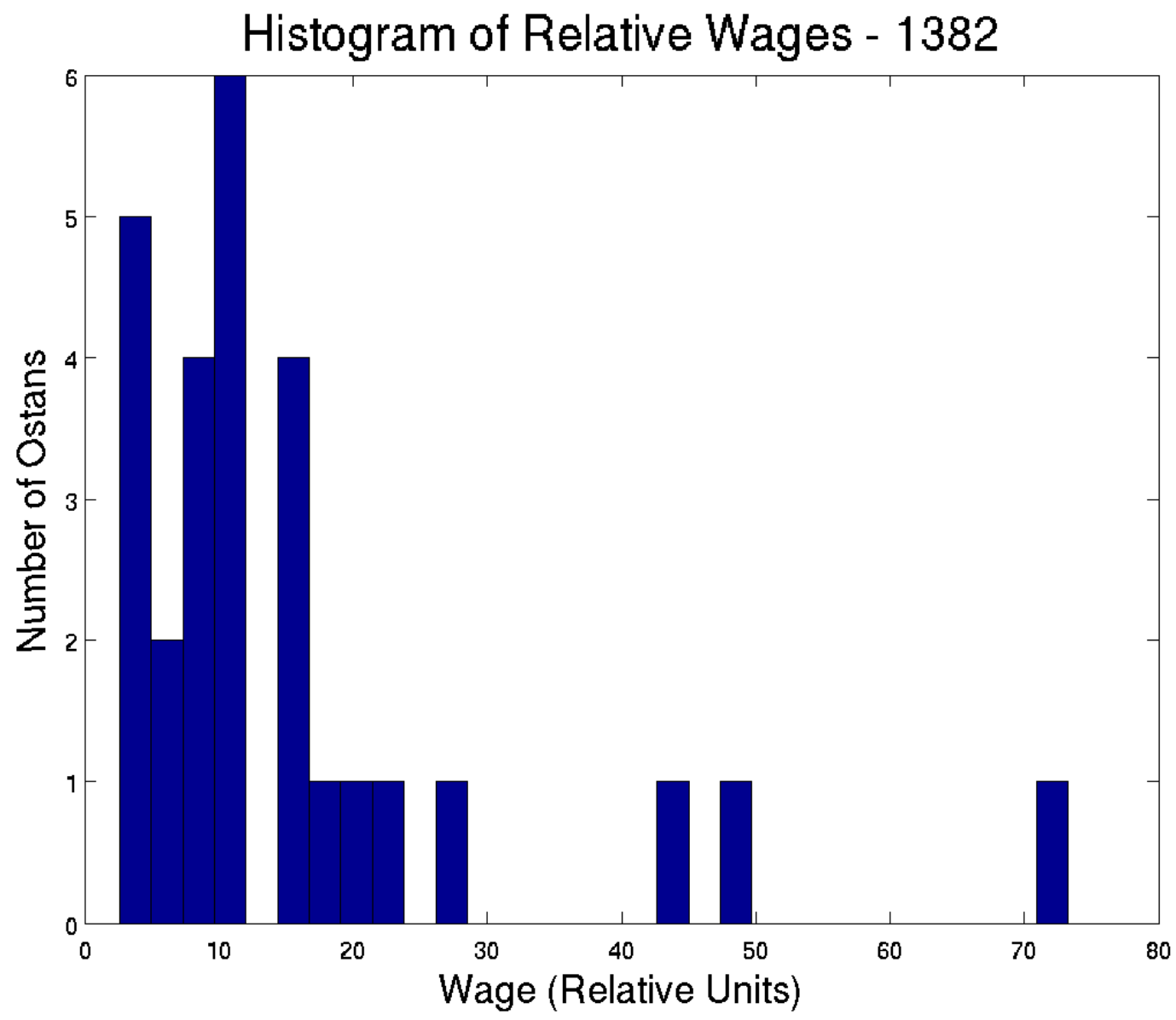

Figure 9. Urban Wage histogram - 1382 